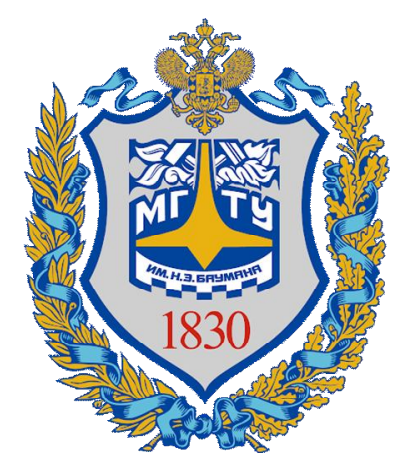

ФЕДЕРАЛЬНОЕ ГОСУДАРСТВЕННОЕ БЮДЖЕТНОЕ

ОБРАЗОВАТЕЛЬНОЕ УЧРЕЖДЕНИЕ ВЫСШЕГО ОБРАЗОВАНИЯ

"МОСКОВСКИЙ ГОСУДАРСТВЕННЫЙ ТЕХНИЧЕСКИЙ УНИВЕРСИТЕТ

ИМЕНИ Н.Э. БАУМАНА

(НАЦИОНАЛЬНЫЙ ИССЛЕДОВАТЕЛЬСКИЙ УНИВЕРСИТЕТ)"

Мытищинский филиал МГТУ им. Н. Э. Баумана

\author{
Е.А. Тихомиров
}

\title{
ЭКОНОМИЧЕСКАЯ ГЕОГРАФИЯ
}

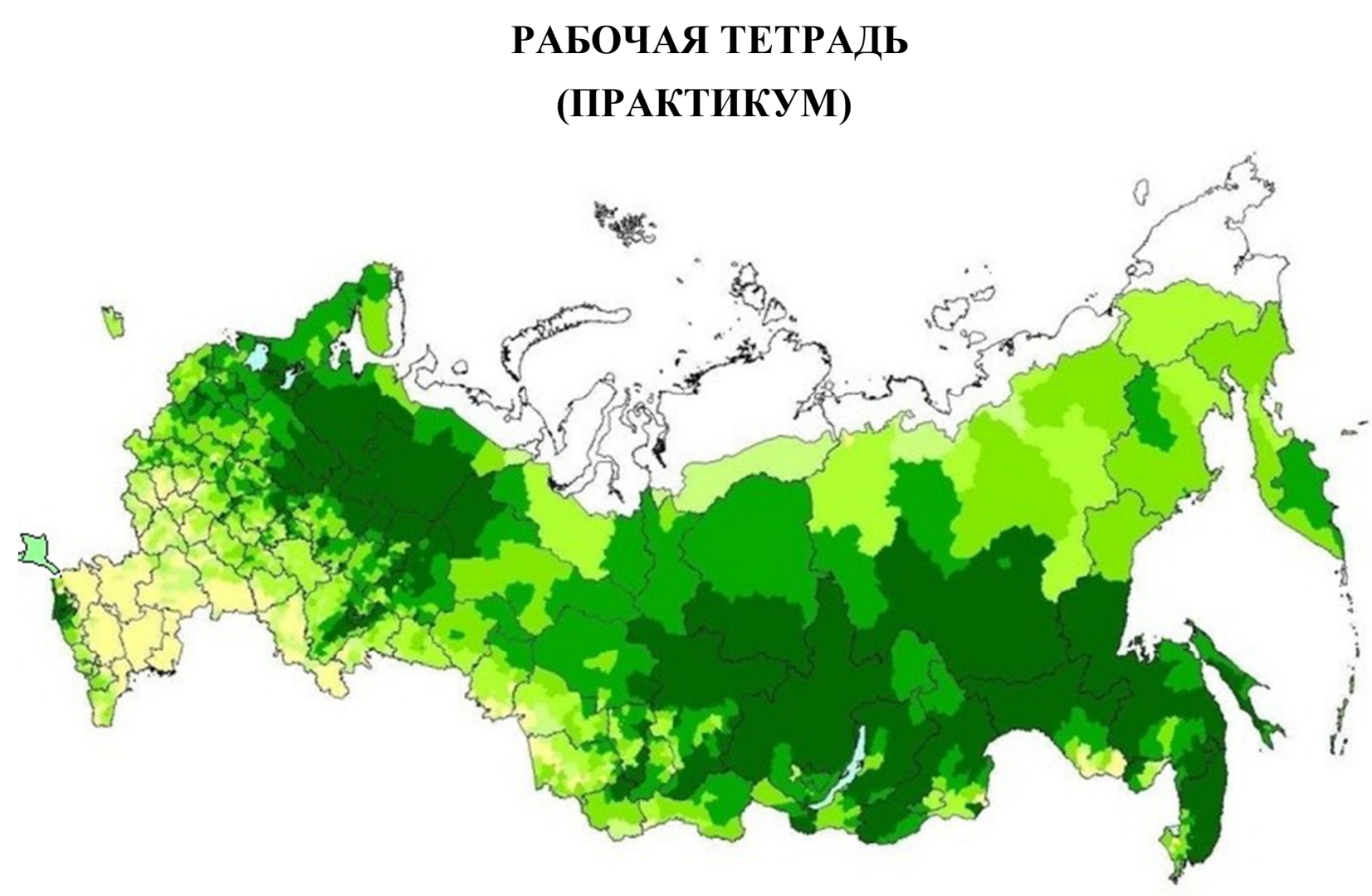

Студент

Группа

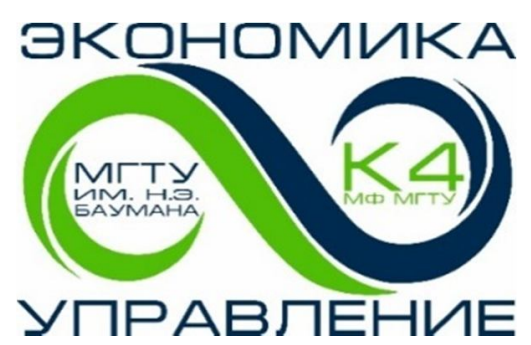

Научно-инновационный центр

Красноярск, 2020 
ФЕДЕРАЛЬНОЕ ГОСУДАРСТВЕННОЕ БЮДЖЕТНОЕ ОБРАЗОВАТЕЛЬНОЕ УЧРЕЖДЕНИЕ ВЫСШЕГО ОБРАЗОВАНИЯ

"МОСКОВСКИЙ ГОСУДАРСТВЕННЫЙ ТЕХНИЧЕСКИЙ УНИВЕРСИТЕТ

ИМЕНИ Н.Э. БАУМАНА

(НАЦИОНАЛЬНЫЙ ИССЛЕДОВАТЕЛЬСКИЙ УНИВЕРСИТЕТ)"

Мытищинский филиал МГТУ им. Н. Э. Баумана

Е.А. Тихомиров

\title{
ЭКОНОМИЧЕСКАЯ ГЕОГРАФИЯ
}

\author{
РАБОЧАЯ ТЕТРАДЬ \\ (ПРАКТИКУМ)
}

Научно-инновационный центр

Красноярск, 2020 


\section{УДК 332.01 (075.8) \\ ББК 65.04(2РОС) я73 \\ T46}

\section{Рецензенты:}

к.э.н., доцент Е.Б. Назаренко, зав. кафедрой К4 «Экономика и Управление» МФ МГТУ им. Н.Э. Баумана;

к.э.н., доцент А.А. Букова, доцент кафедры К4 «Экономика и Управление» МФ МГТУ им. Н.Э. Баумана

Подготовлено на кафедре К4 «Экономика и управление» Мытищинского филиала МГТУ им. Н.Э. Баумана.

Одобрено и рекомендовано к изданию в качестве учебно-методического пособия Редакиионно-издательским советом университета.

Тихомиров, E.A.

T46 Экономическая география: рабочая тетрадь (практикум) / Е.А. Тихомиров. Красноярск: Научно-инновационный центр, 2020. - 206 с.

\section{ISBN 978-5-907208-30-8}

DOI: 10.12731/978-5-907208-30-8

Рабочая тетрадь (практикум) по экономической географии предназначена для организации самостоятельной работы студентов. Задания, предлагаемые в рабочей тетради, помогут систематизировать полученные знания и развить экономикогеографическое мышление. Преподавателю рабочая тетрадь поможет лучше организовать семинарские занятия, сделать их более интенсивными и интересными.

Разработано в соответствии с ФГОС ВО на основе примерной программы дисциплины «Экономическая география» для направления подготовки 38.03 .01 «Экономика».

ISBN 978-5-907208-30-8

(C) Тихомиров Е.А., 2020

(C) Научно-инновационный центр, 2020

(с) Мытищинский филиал МГТУ им. Н. Э. Баумана, 2020 


\section{СОДЕРЖАНИЕ}

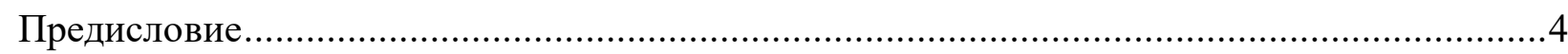

Тема 1. Теоретические основы экономической географии и регионалистики.......................7

Тема 2. Историческая и политическая география. Состав и географическое положение

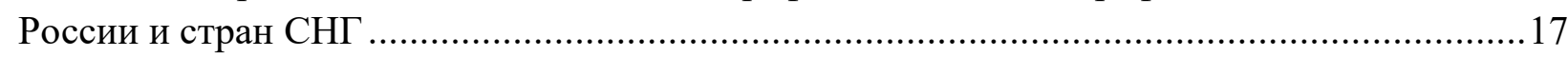

Тема 3. Природные условия и природные ресурсы России. Природно-ресурсный потенциал как условие организации народного хозяйства России …...............................36

Тема 4. Основные отрасли промышленности. Топливно-энергетический комплекс.

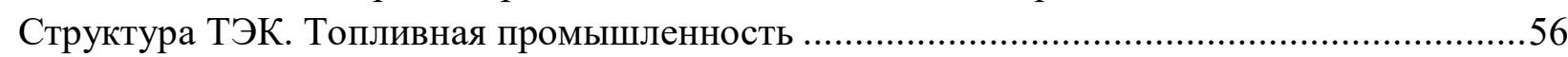

Тема 5. Основные отрасли промышленности. Металлургический комплекс.

Машиностроительный комплекс. Оборонно-промышленный комплекс. Химический комплекс.

Тема 6. Основные отрасли промышленности. Агропромышленный комплекс (АПК).

Перерабатывающие отрасли. Транспортный комплекс .............................................93

Тема 7. Лесное хозяйство и лесопромышленный комплекс. Рекреационная сфера ...........112

Тема 8. Население и трудовые ресурсы ...................................................................... 129

Тема 9. Административное и экономическое деление Российской Федерации.................. 153

Темы эссе по курсу «Экономическая география» ............................................................ 183

Темы рефератов по курсу «Экономическая география» ................................................ 186

Презентационный доклад по курсу «Экономическая география» ................................... 193

Примерный перечень вопросов к экзамену по дисциплине «Экономическая география» 198

Текущий контроль успеваемости и промежуточная аттестация обучающихся по

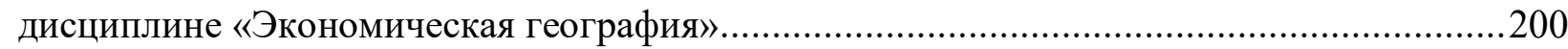

Текущий контроль успеваемости обучающихся ........................................................200

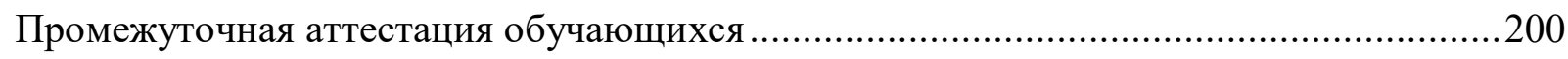

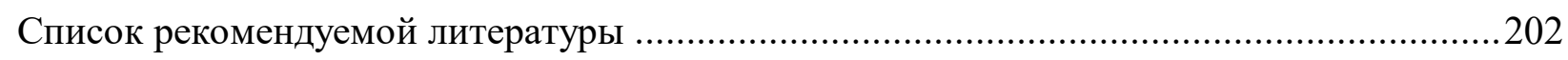

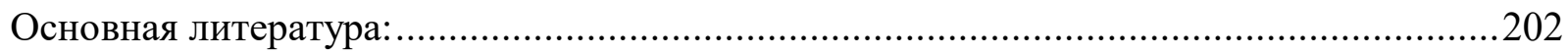

Ресурсы информационно-телекоммуникационной сети «Интернет» и другие электронные информационные источники 